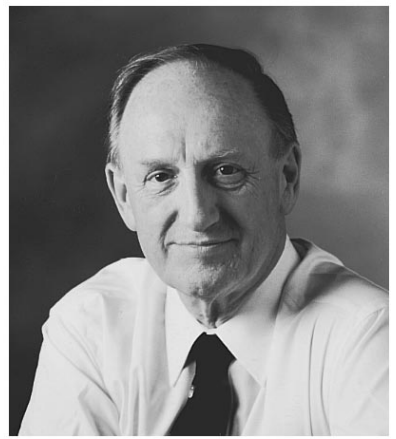

\section{The Kingslake Medal and Prize 1995}

We now have a tradition of announcing the selection of the recipient of the Kingslake Medal and Prize in the August issue of Optical Engineering. The timing is such that it coincides with the actual award of the medal and prize at the annual meeting of the society, which will be held in Denver this year.

Our congratulations for the most outstanding paper to be published in Optical Engineering in Volume 34 during 1995 goes to four coauthors listed below. And the winner is: "Random transparency targets for modulation transfer function measurements in the visible and infrared regions,' by Arnold Daniels, Glenn D. Boreman, Alfred D. Ducharme, and Eyal Sapir, Optical Engineering 34(3), 860-868 (1995). The first three authors are at the University of Central Florida and the fourth author is with CI Systems, Inc. in California.

This award is an important part of the publication program of Optical Engineering. Each year the winners attest to the quality of your journal. On behalf of our readers and colleagues, I thank the members of the Kingslake Award Committee for their diligent efforts. John Grievenkamp chaired the committee and the members were Ed English, Groot Gregory, Russ Palum, and Bill Sweatt. In choosing this year's winning paper, the committee made the following comments:

We nominate this paper because of its overall excellence. It addresses a broad, timely and interesting problem in optical testing. The level of the paper is well balanced to allow any member to understand the topic and follow the progress from the introduction through the experimental results. This random target method measures the MTF over the entire image area at all frequencies and does not require the precise image feature extraction that is needed for MTF measurements using a tilted edge, square wave or sine wave target.

The authors describe a new and clever method of solving an old problem. The technique is presented with an adequate amount of theory supported by an extensive number of experiments. This topic has applicability to many fields. While the science of the paper is not radically new, the paper does tie together a number of concepts, and it provides a methodology that is applicable to a manufacturing environment with advantages over current MTF measurement techniques. Many practical optical engineering issues are covered, and the overall message of the paper is that this method works!

Brian J. Thompson Editor

\begin{tabular}{|llll|}
\hline \multicolumn{1}{|c|}{ Rudolf Kingslake Medal and Prize-Past Recipients } \\
\hline 1974 & Irving R. Abel and B. R. Reynolds & 1986 & \multicolumn{1}{c|}{ Arthur D. Fisher, Lai-Chang Ling, John N. Lee, } \\
1975 & J. M. Burch and C. Forno & & and Robert C. Fukuda \\
1976 & Richard E. Swing & 1987 & Chris P. Kirk \\
1977 & David B. Kay and Brian J. Thompson & 1988 & Ares J. Rosakis, Alan T. Zehnder, and \\
1978 & Norman J. Brown & & Ramaratnam Narasimhan \\
1979 & J. R. Fienup & 1989 & Pochi Yeh, Arthur Chiou, John Hong, Paul H. \\
1980 & G. Ferrano and G. Hausler & & Beckwith, Tallis Chang, and Monte Khoshnevisan \\
1981 & Robert A. Sprague and William D. Turner & 1990 & Paul. R. Prucnal and Philippe A. Perrier \\
1982 & David M. Pepper & 1991 & Brian E. Newman \\
1983 & James R. Palmer & 1992 & Aden B. Meinel and Marjorie P. Meinel \\
1984 & Gene R. Gindi and Arthur F. Gmitro & 1993 & Harvey M. Phillips and Roland A. Sauerbrey \\
1985 & Armand R. Tanguay, Jr. & 1994 & Jose M. Sasian \\
\hline
\end{tabular}

